\title{
Mandatory Processing of Implied Content: Lessons from Context Effects
} on Implicitures

Dorjee, D.; Garrett, M.F.; Harnish, R.M.

\section{International Review of Pragmatics}

\author{
DOI: \\ $10.1163 / 18773109-13050204$
}

Published: 01/01/2013

Peer reviewed version

Cyswllt i'r cyhoeddiad / Link to publication

Dyfyniad o'r fersiwn a gyhoeddwyd / Citation for published version (APA):

Dorjee, D., Garrett, M. F., \& Harnish, R. M. (2013). Mandatory Processing of Implied Content: Lessons from Context Effects on Implicitures. International Review of Pragmatics, 5(2), 217-232. https://doi.org/10.1163/18773109-13050204

\footnotetext{
Hawliau Cyffredinol / General rights

Copyright and moral rights for the publications made accessible in the public portal are retained by the authors and/or other copyright owners and it is a condition of accessing publications that users recognise and abide by the legal requirements associated with these rights.

- Users may download and print one copy of any publication from the public portal for the purpose of private study or research.

- You may not further distribute the material or use it for any profit-making activity or commercial gain

- You may freely distribute the URL identifying the publication in the public portal ?
}

Take down policy

If you believe that this document breaches copyright please contact us providing details, and we will remove access to the work immediately and investigate your claim. 
Implied content and context

Mandatory processing of implied content:

Lessons from context effects on implicitures

\author{
Dusana Dorjee \\ Bangor University, Bangor, UK \\ Merrill F. Garrett \\ University of Arizona, Tucson, USA
}

Robert M. Harnish

University of Arizona, Tucson, USA

Corresponding author:

Dusana Dorjee, Ph.D.

School of Psychology

Bangor University

LL57 2AS Bangor

United Kingdom

Phone: +44-1248-383-858

Fax: $\quad+44-1248-382-599$

E-mail:․dorjee@bangor.ac.uk 
Implied content and context

\section{Abstract}

Since early experimental explorations of pragmatic phenomena it has been documented that novel and established utterances are processed differently. This is especially relevant to processing of a class of utterances called 'implicitures' (Bach, 1994) in which some aspects of content are not explicitly expressed by the words used -- they are implicit. It has been suggested that at least some implicitures have become 'standardized' for their content (Bach, 1998; Garrett \& Harnish, 2007). That is, the standard use of these expressions conveys the relevant content even though the words uttered do not present that content as conventional, linguistic meaning. While some studies suggest that the implicitures are mandatorily inferred regardless of context (Bach, 1998), others claim that impliciture processing is context-dependent (Sperber \& Wilson, 1986). We investigated this issue using spatial, temporal and possession implicitures in two reaction time experiments. Implicitures were presented context-free or embedded in contexts that either supported their preferred interpretation or cancelled it. The results indicated that implicitures are readily available when no context is provided and are produced even when context forces an alternative interpretation. These findings support a standardization view for at least some impliciture processing. Possible differences in processing mechanisms across theories of impliciture processing and across impliciture types are discussed.

Keywords: Language pragmatics; implicitures; language in context; standardization; enriched meanings 
Implied content and context

\section{Introduction}

We sometimes mean almost exactly what we say (literally and directly), sometimes more than what we say (indirection and implicature), and sometimes we don't mean what we say at all (nonliterality). It is often clear which category a particular utterance belongs to, but in many cases linguistic or psychological evidence must be brought to bear. One interesting and important class of overlapping cases goes by different labels: 'generalized conversational implicatures' (Grice, 1975), 'explicatures ' (Sperber \& Wilson, 1986), 'enriched sayings' (Recanati, 1993), ‘implicitures' (Bach, 1994), and 'Q/I/M implicatures' (Levinson, 2000). We adapt Bach's term 'impliciture' to cover these cases because it conveys the central idea that in such utterances, what is directly meant is implicit in what is said and is not figured out subsequently. For example, the utterance 'It's raining' typically involves a reference to local weather rather than weather at some other location. Furthermore, what is said as well as what is directly meant is closely connected to the words uttered and their syntactic structure (Grice, 1975). This distinguishes implicitures from traditional categories of conversational implicatures, indirect speech, and nonliteral utterances, originally investigated by Clark and Lucy (1975), Gibbs (1979) and Ortony, Schallert, Reynolds and Antos (1978).

Experimental research on implicitures asks how such implicit information is recovered during sentence processing. Different mechanisms have been proposed: Griceans postulated flouting Conversational Maxims, Sperber and Wilson proposed a Principle of Relevance, Bach proposed Standardized uses/meanings, and Levinson Default Heuristics. According to the relevance view (Sperber \& Wilson, 1986) implicitures are only derived if favoured by context, so no interference would be 
Implied content and context

expected from an impliciture in a context favouring an alternative interpretation. In contrast, the standardization account (Bach, 1998) taking standardized uses as more salient than non-standardized uses (Garret \& Harnish, 2007), suggested that the implied meaning is bound to sentence form and computed whenever an impliciture is encountered regardless of the context. Finally, according to the default view, implied content is computed when context does not restrict the interpretation but is suspended when the context forces an alternative (Levinson, 2000).

Bezuidenhout and Cutting (2002) used on-line reading times for implicitures embedded as final sentences in short contexts to test three processing models derived from a default view, relevance theory and Gricean theory (not considered here). The contexts favoured either content close to sentence meaning, often called the "minimal" interpretation, or an enriched interpretation, the impliciture. The results showed speeded processing for contexts supporting the enriched meanings. This suggests processing that assigns priority to the impliciture regardless of context. Bezuidenhout and Cutting (2002) presented this outcome (which they described in terms of a 'ranked parallel model') as compatible with a default view (Levinson, 2000), but such interpretation is somewhat controversial given that Levinson postulates suspension of impliciture defaults in contexts supporting alternative interpretations. This is perhaps due to two versions of the default theory being in play here, one (as exemplified by Bezuidenhout and Cutting's treatment) that is not suspended by context and one (as exemplified in Levinson, 2000) that is. We will return to this issue in the discussion.

Subsequent studies focusing on a specific subgroup of implicitures called 'scalars' (e.g. 'Some elephants have trunks'), have produced results that differ from those obtained by Bezuidenhout and Cutting (2002). Truthfulness judgment reaction 
Implied content and context

time studies (Bott \& Noveck, 2004) as well as reading time studies with scalars (Breheny, Katsos \& Williams, 2006) showed that the implied meanings were not automatically derived in scalars, but were instead context dependent. This contradicting pattern of results has been attributed to differences in the impliciture types examined in the studies. The research supporting the relevance view (Bott $\&$ Noveck, 2004; Breheny, Katsos \& Williams, 2006) used only scalars, while Bezuidenhuit and Cutting (2002), following Gibbs and Moise (1997), used impliciture types other than scalars and did not systematically distinguish among them.

Here the distinction drawn by Garrett and Harnish (2009), following Levinson, between 'Q-phenomena' and 'I-phenomena' seems to be useful. Levinson's 'QHeuristic" applies to contrast sets (e.g., words like some < all'; 'or $<$ and'; 'try $<$ succeed') which provide linguistic alternations that can direct ordered inferences. The "I-Heuristic", by contrast, refers to default inferences applied to utterances reporting stereotypical situations. Hence I-heuristic does not appeal to specific alternative expressions the way the Q-Heuristic does, but rather relies on 'typical ways of reporting typical states of affairs' and so has a far greater potential interaction with background knowledge.

While some implicitures from Bezuidenhout and Cutting's (2002) study, such as 'It's raining', would fall into the I-phenomena category, scalars used in other studies would fall into the group of Q-phenomena. Mechanisms underlying processing of these two categories of implicitures seem likely to differ precisely because of differences in their links to contextual constraint.

Garrett and Harnish (2007) investigated a subclass of I-phenomena, involving examples such as locative ('It's raining'), temporal ('I've had breakfast') and possession ('She flexed a leg'), each of which may have a minimal or enriched 
Implied content and context

impliciture interpretation. Here the theoretical contrast was between the account of default heuristics with suspension and the proposal that meanings of implicitures in the I-phenomena category are derived based on standardized uses. Garrett and Harnish (2007) used two measures: reading time for implicitures and speeded response time to probe questions immediately following the impliciture.

When these sentences were presented context-free, there was a clear preference for their enriched interpretations. Furthermore, and essential to the contextual issues, these enriched interpretations interfered with impliciture processing when they were embedded in contexts favouring their minimal interpretations. Those contexts did not suspend the inpliciture. This effect was observed for the question answering measure. However, the reading time measure for the impliciture sentence did not reach significance, and hence there was no demonstration of an immediate clash between context and the standardized content for the impliciture. Bezuidenhout and Cutting did find such an effect on reading time for the materials they tested. It is, therefore, important to evaluate this issue more robustly to better understand the time course of impliciture processing.

The current study aimed to replicate and extend the previous investigation by Garrett and Harnish (2007) through refined experimental procedures and testing materials. The first experiment in Garrett and Harnish (2007) which tested for context-free interpretations of implicitures used auditory presentation of impliciture sentences while the second experiment with implicitures embedded in contexts relied on visual presentation of stimuli. To minimize possible discrepancies in findings arising from the modality differences, the current study used the visual reading mode only. The following experiments also included a more extensive item set and tested larger participants sample than the original study by Garrett \& Harnish (2007). 
Implied content and context

Additionally, in the context of this study we also wish to highlight the distinctions between default, relevance and standardization theories of impliciture processing. Two experiments are reported. The purpose of the first experiment was to establish dominant interpretations of implicitures when context does not influence the meaning selection. The second experiment examined effects of context reading time, impliciture reading time and interpretation decision time for implicitures embedded in contexts supporting or canceling their implied meanings.

\section{Experiment 1}

This experiment assessed predictions of default views (Levinson, 2000) and standardization (Bach, 1998) by examining context-free interpretations of implicitures. Both approaches maintain that implicitures are computed automatically in these situations, and should thus be produced even when context cannot guide the interpretation. The position of the relevance account on this is not clear, perhaps context-free occurrences of implicitures would be considered ambiguous since context-dependent processes needed for inferring them are absent. This is because an utterance without strongly implicated premises is subject to application of a wide range of premises that are likely to vary across people (Sperber \& Wilson, 1995: 199200).

\subsection{Materials and methods}

\subsubsection{Participants}


Implied content and context

The study, including the norming phase, Experiment 1 and Experiment 2, was approved by the relevant research ethics body at the University of Arizona prior to its start. 40 native speakers of English (10 males, 30 females; average age 20, age range 18-24), without history of language or learning disabilities participated in this experiment. Participants were undergraduates at the University of Arizona and received a course credit for their participation. At the beginning of each testing session, including norming, informed consent was obtained from each participant.

\subsubsection{Stimuli}

\section{Norming phase:}

To ensure good quality of impliciture sentences to be used in Experiments 1 and 2, eighty two impliciture candidates and their control sentences matched for length and structure were generated by the researchers and presented to a separate group of native speakers of English (undergraduates at the University of Arizona participating in the experiment for a course credit) in a paper and pencil task. The objective was to measure the interpretive bias for the impliciture content. Twenty four items out of the set were previously used by Garrett and Harnish (2007). Each sentence was followed by a question about the implied content and two possible answers -- an impliciture probe and a non-impliciture probe. Responses were scored as accurate if the impliciture probe was selected. Data from 14 participants with overall accuracy rates $80 \%$ or better were included in the final evaluations. Items with error rates higher than $20 \%$ were excluded, leading to a set of 60 implicitures and control sentences. This resulted in an accuracy rate of $95 \%$ in favour of the impliciture probe across the set of impliciture sentences. The selected items were further 
Implied content and context

evaluated in two additional pilot runs using a computer based speeded two-alternative forced choice task which followed the procedures of the main experiment. For this part of norming, data from 46 native speakers of English (undergraduates at the University of Arizona participating in the experiment for a course credit) with accuracy rates over $80 \%$ for impliciture candidates were included in the final analyses. Average bias for impliciture content across the full set of impliciture items in this timed task was $89.2 \%$. As a result of this final phase of norming five items with lowest accuracy rates were replaced.

\section{Final set of stimuli:}

Based on the results of the norming phase, 60 impliciture sentences of three implicitures types (20 locative, 20 temporal, and 20 possession) were selected for the experiment. Additional 60 filler sentences of comparable length and structure without strongly implied meanings were included in the testing set (e.g., "It's a beautiful butterfly."). 24 filler items were also included to avoid strategic response bias. Each item was followed by a question word with impliciture and non-impliciture response displayed underneath (see Figure 1).

[Fig. 1 inserted here]

\subsubsection{Procedure}

Participants were seated in front of a computer screen in a sound attenuated room and stimuli were presented visually on the computer screen. DMDX software was used in this and all other testing involving computer presentation of stimuli 
Implied content and context

(Forster \& Forster, 2003). Participants were instructed to imagine the experimental sentences being uttered in a natural conversation. Presentation sequence for each item (outlined in Figure 1) started with the phrase 'Somebody said:' displayed for $500 \mathrm{~ms}$. Subsequently, an impliciture sentence or a filler sentence was presented. After reading the sentence participants pressed a spacebar on a keyboard to advance to the question display. There they selected a response by pressing one of two keys with either the index finger or the middle finger of their right hand. Participants' responses were recorded. This experiment took 20-25 min to complete.

\subsection{Results}

Responses were scored as accurate if they matched the preferred interpretation determined in the norming phase. The average error rate for free-standing implicitures was $12 \%$ reflecting the average bias of $88 \%$ in favour of the impliciture probes. Participants made the highest number of errors on temporal implicitures and were most accurate on locative implicitures (see Table 1). The individual error rates ranged from $19 \%$ to $1 \%$. All error trials and reaction times below $200 \mathrm{~ms}$, above $4000 \mathrm{~ms}$ and below or above two standard deviations from the mean were excluded from the reaction time analyses. A one-way within-subjects analysis of variance was conducted to test the accuracy differences across the three subtypes. The main-effect of impliciture type was significant $(\mathrm{F}(2,78)=11.11, \mathrm{p}<.001)$. The accuracy was highest for locative implicitures (93\%) and lowest for temporals (83\%). The average accuracy rate for possession implicitures was $89 \%$.

\subsection{Discussion}


Implied content and context

Results of this experiment replicated the findings by Garrett and Harnish (2007). Using a visual paradigm and a larger set of items and with higher number of participants, we found that the preferred interpretations of locative, temporal and possession sentences involve implicitures when they are presented without context. This supports the predictions of default accounts (Levison, 2000) and the standardization theory (Bach, 1998) both of which suggest that the impliciture interpretation is computed mandatorily when a context does not restrict the interpretation.

\section{Experiment 2}

Experiment 1 established a benchmark for performance with context-free implicitures. The purpose of the second experiment was to investigate the availability of the dominant meanings when implicitures are embedded in short contexts. The contexts were constructed so that they either matched the contents of context-free implicitures (enabling contexts), or favoured an alternative interpretation of implicitures contradicting their context-free meanings (canceling contexts). Underlying processing was examined using three on-line measures - context reading time, impliciture reading time and decision reaction time. According to the relevance view (Sperber \& Wilson, 1986), no differences in processing would be expected between implicitures embedded in enabling and canceling contexts. This is because meaning of impliciture sentences is determined by the context in which they are placed and evolves as individual lexical items are encountered. Similarly, the default with suspension view (Levinson, 2000) suggests that default heuristics producing the 
Implied content and context

implicitures will be suspended in contexts supporting an alternative interpretation and therefore, no difference between the enabling and canceling contexts would be expected. In contrast, the default without suspension theory (Bezuidenhout \& Cutting, 2002) and the standardization view (Bach, 1998) predict that the context-free preferred interpretations of implicitures will be inferred regardless of contexts in which they are placed. Thus a slowdown in processing would be expected when there is a mismatch between context meaning and impliciture meaning (as in the canceling condition).

\subsection{Materials and methods}

\subsubsection{Participants}

The same group of 40 young adults that participated in Experiment 1 was tested.

\subsubsection{Stimuli}

\section{Norming Phase:}

Impliciture sentences used in Experiment 1 were now embedded in canceling and enabling contexts. Prior to Experiment 2 off-line as well as computer-based evaluations were used to ensure quality of the stimuli. Contexts were 40 to 70 words in length and each context pair was matched for length and complexity. Materials were divided into two counterbalanced files so that each participant was exposed to each impliciture only once. Participants selected an impliciture or a non-impliciture 
Implied content and context

probe based on their interpretation of each context. Data from 83 participants with error rates less than $10 \%$ was used in the off-line paper and pencil evaluation. In the computer-based norming, data from 67 participants with overall error rates below $20 \%$ were included. All participants in the norming phase were undergraduates at the University of Arizona fulfilling a course requirement. Only contexts with error rates less than $10 \%$ were selected for Experiment 2 resulting in the final set of 120 contexts (60 enabling and 60 canceling) with 60 implicitures as final sentences.

Final set of stimuli: The 60 context pairs selected in the norming phase were divided into two counterbalanced lists - each of the lists contained 20 locative, 20 temporal and 20 possessive contexts, with half of the contexts in each type being canceling and half enabling (see examples in Figure 2). The contexts were pseudorandomly organized so that responses to the same impliciture group and button presses of the same type would not be immediately repeated more than three times. Each item was followed by a question word with an impliciture response and a nonimpliciture response displayed underneath.

\subsubsection{Procedure}

All stimuli were presented visually on a computer screen in a self-paced reading paradigm. Participants had to press a keyboard key with their left hand to advance through the contexts line by line. The lines stayed on the screen until the final button press indicating that the last sentence in the context had been read. After that question display was presented where participants selected a response by pressing one of two keys either with the index finger or the middle finger of their right hand. Each 
Implied content and context

context consisted of nine lines and an impliciture was always displayed in the final line. Participants' responses, in addition to their context reading times, impliciture reading times, and decision times, were recorded. The context reading time was measured as the average reading time per line for the first eight lines of the context up to the final impliciture sentence. The impliciture reading time was the interval from the display of the impliciture sentence in the last line until the button press after the sentence had been read. Decision time was measured from the onset of the question display with impliciture and non-impliciture probes until a response was selected by a button press. This experiment immediately followed Experiment 1 and took 25-30 minutes to complete.

[Fig. 2 inserted here]

\subsection{Results}

The average error rate for implicitures embedded in contexts was $7 \%$, with participants making more errors on canceling (12\%) than enabling contexts (3\%). The overall error rates for individual participants ranged from $19 \%$ to $0 \%$. Interpretation success rates across context and implicitures types are summarized in Table 1.

All error trials were excluded from reaction time analyses. In addition, reading time and decision time cut-offs of two standard deviations from the mean and also lower and higher cut-offs of $200 \mathrm{~ms}$ and $4000 \mathrm{~ms}$ were applied to the data. The outliers resulting from the cut-offs were excluded from the analyses. The reaction time and reading time results are summarized in Table 2. 
Implied content and context

[Table 1 inserted here]

[Table 2 inserted here]

Context reading time: Two-way repeated measures analyses of variance (ANOVAs) with context type (Two levels: enabling and canceling) and impliciture type (Three levels: locative, temporal, possession) as factors were conducted. There was no significant effect for the context type factor. The main effect for impliciture type was significant $(\mathrm{F} 1(2,78)=86.77, \mathrm{p}<.001 ; \mathrm{F} 2(2,38)=3.86, \mathrm{p}<.05)$ reflecting a gradient from fastest reading of contexts for locatives to slowest reading of contexts containing temporal implicitures. Interaction between the two factors was not significant $(\mathrm{F} 1(2,78)=.22, \mathrm{p}<.80 ; \mathrm{F} 2(2,38)=.03, \mathrm{p}=.97)$

Impliciture reading time: $2 \times 3$ ANOVAs with the same factors of context type and impliciture type were conducted and revealed a marginally significant main effect of context type by subjects and a significant effect by items $(F 1(1,39)=3.87$, $\mathrm{p}=.056 ; \mathrm{F} 2(1,19)=5.36, \mathrm{p}<.05)$. This reflected slower reading times for implicitures in canceling contexts than those in enabling contexts. The main effect of impliciture type was significant only in the subject analyses $(\mathrm{F} 1(2,78)=16.16, \mathrm{p}<$ $.001 ; \mathrm{F} 2(2,38)=2.27, \mathrm{p}=.12)$. Interaction between the two factors was marginally significant by subjects only $(\mathrm{F} 1(2,78)=2.99, \mathrm{p}<.056 ; \mathrm{F} 2(2,38)=2.21, \mathrm{p}=.12)$. Separate t-tests exploring differences in reading times for the three types of implicitures in enabling and canceling contexts showed significant effects for temporals $(\mathrm{t} 1(39)=2.44, \mathrm{p}<.01 ; \mathrm{t} 2(19)=.73, \mathrm{p}=.24)$ and possession implicitures $(\mathrm{t} 1(39)=1.97, \mathrm{p}<.05 ; \mathrm{t} 2(19)=3.20, \mathrm{p}<.01)$, but not locatives. 
Implied content and context

Decision reaction time: $2 \times 3$ ANOVAs with the factors of sentence type and impliciture type were calculated. There was a significant effect of context type (F1) 1 , $39)=22.77, \mathrm{p}<.001 ; \mathrm{F} 2(1,19)=15.8, \mathrm{p}<.01)$ with decisions to implicitures in enabling contexts being made significantly faster than to implicitures in canceling contexts. The main effect for impliciture type was also significant $(\mathrm{F} 1(2,78)=46.70$, $\mathrm{p}<.001 ; \mathrm{F} 2(2,38)=36.87, \mathrm{p}<.0001)$. There was a significant interaction between the two factors $(\mathrm{F} 1(2,78)=6.18, \mathrm{p}<.01 ; \mathrm{F} 2(2,38)=4.05, \mathrm{p}<.05)$. Separate t-tests conducted for context effects within impliciture subtypes revealed differences between locatives $(\mathrm{t} 1(39)=2.21, \mathrm{p}<.05 ; \mathrm{t} 2(19)=1.14, \mathrm{p}=.27)$, temporals $(\mathrm{t} 1(39)=$ $4.81, \mathrm{p}<.01 ; \mathrm{t} 2(19)=4.89, \mathrm{p}<.01)$ and possession implicitures $(\mathrm{t} 1(39)=2.29, \mathrm{p}<$ $.05 ; \mathrm{t} 2(19)=1.23, \mathrm{p}=.24)$.

\subsection{Discussion}

Results of Experiment 2 replicated findings obtained by Garrett and Harnish (2007) for decision reaction time in a visual paradigm -- participants took significantly longer to choose a probe for the context appropriate interpretation of implicitures in contexts forcing a non-enriched interpretation of an impliciture. In addition, the current experiment showed a significant effect in the same direction for sentence reading time; this latter comports with findings by Bezuidenhout and Cutting (2002). Further, there was no effect of context reading time. This result was expected provided that the enabling and canceling pairs of contexts were well matched on length and complexity. Overall, these measures of impliciture processing provide a consistent picture indicating a process that assigns enriched content to implicitures and does so even in contexts which are incompatible with that content. 
Implied content and context

\section{General Discussion}

The predictions of default account (Levison, 2000), relevance theory (Sperber \& Wilson, 1986) and standardization account (Bach, 1998) were assessed in two experiments. Experiment 1 found that spatial, temporal and possession implicitures have a dominant implied interpretation that is assigned when they are presented without context. This indicates that the impliciture is computed automatically without the necessity of contextual contribution. Such a result supports predictions of the standardization account and the default accounts, but does not distinguish between them.

The second experiment tested whether these same implicitures are available even when context favours an alternative interpretation. Results of Experiment 2 indicated that this indeed is the case: reading of the implicitures took longer in contexts contradicting the enriched meaning, and interpretation decisions were also slower in this condition. This finding is expected on the standardization account and on the processing model in Bezuidenhout and Cutting (2002). The default with suspension account, which is the original default view expressed in Levinson (2000), would on the other hand, predict the suspension mechanism to apply in the canceling contexts, resulting in the default not being computed. Since no delay would be expected in this case, the default with suspension account is not compatible with our results.

A number of questions emerge as candidates for further research. First, we note that Bezuidenhout and Cutting linked their model to a default perspective, but that model requires a 'default' that is invariably computed and not suspended by 
Implied content and context

context, hence not at all a default in Levinson's terms. Thus, for both standardization and default sans suspenders, the outcome is driven by the form of the impliciture and its content is automatically enriched. The only difference between the two lies in the mechanism assumed, standardization or inference to a default value. The available data does not distinguish those two possibilities. Experimental evaluation of these options might benefit from more precise time based measures such as event-related brain potentials that could potentially resolve the question of when enriched content becomes available. On the assumption that an inference represents an added processing step, it would appear later and/or demand additional processing resources as compared with standardization.

In this context we should consider some indications that there may indeed be further processing differences within the set of exemplars that we have been labelling I-phenomena. Some of these may prove to be more akin to inferential processes, while others will better fit the mould of standardization. In our experimental results, we found that the strength of the implied interpretations varied across the three impliciture types examined. Context-free, there was highest interpretive bias for locative implicitures and lowest for temporals. In context, interpretation of temporals embedded in canceling contexts resulted in slow-down on impliciture sentence reading and on interpretation decision times. But interference from interpretation of locatives was much less obvious, only significant for participant decision times. Possession implicitures were slowed by context interpretation when they were encountered in the context-final sentence, but did not cause a slow down on the interpretation decision time measure. These differences are only suggestive, of course, as they are post hoc observations. But, they do point to possible processing 
Implied content and context

differences between the impliciture subtypes in the I-phenomena group and such differences, if they prove to be systematic, may provide leverage for better dissecting underlying processing mechanisms.

A second class of questions asks how the results concerning I-phenomena relate to the better studied Q-phenomena (see examples 1 and 2)

(1) Q-phenomena (Scalars)

Some of the guests have left

a. Minimal interpretation: Some of the guests have left, maybe all.

b. Enriched interpretation: Some of the guests have left [but not all]

(2) I-Phenomena

I've had breakfast.

a. Minimal interpretation: I've had breakfast sometime (minimal)

b. Enriched interpretation: I've had breakfast [today]

As Levinson points out, Q-phenomena have a meta-linguistic aspect that I-phenomena lack, due to the fact that Q-implicitures turn on the location of the word(s) on the relevant scale of words. Nothing like this is true of I-phenomena. And Garrett and Harnish (2009) point out, as with standardization, the Q-impliciture choices are limited and tightly connected to the language. Q-implicitures avoid resorting to general problem solving by appealing to a scale fixed in the language; the scale does for Q-impliciture what standardization does for standardized I-implicitures. 
Implied content and context

Finally, we should emphasize that further work in needed to establish how meanings become standardized. It has been suggested that repeated coupling of an expression with an impliciture in usage can lead to attachment of this meaning to the linguistic form (Bach and Harnish, 1979). But exact mechanisms of this process have not been examined closely so far. It is also not clear how the effects of standardization would differ in terms of cognitive processing from products of conventionality (Glucksberg, Gildea \& Bookin, 1982) and establishment of saliency of meanings (Giora, 1999). Distinctions among these terms need to be drawn and experimental studies examining how utterances become standardized, conventionalized or salient are needed. These issues are not only relevant to implicitures, but apply to processing of other kinds of non-literal or indirect pragmatic utterances such as standardized and novel metaphors. Therefore, close attention needs to be paid to standardization of utterances by future studies in order to advance explorations in the field of experimental pragmatics. 
Implied content and context

\section{References:}

Bach, Kent. 1994. Conversational Impliciture. Mind and Language 9: 124-161.

Bach. Kent. 1998. Postscript (1989): Standardization revisited. In A. Kasher (ed.), Pragmatics: Central concepts,712-722. London: Routledge.

Bach, Kent and Robert Harnish. 1979. Linguistic communication and speech acts. Cambridge, MA: MIT Press.

Bezuidenhout, Anne and J. Cooper Cutting. 2002. Literal meaning, minimal propositions, and pragmatic processing. Journal of Pragmatics 34: 433-456.

Bott, Lewis and Ira A. Noveck. 2004. Some utterances are underinformative: The onset and time course of scalar inferences. Journal of Memory and Language 51: 437-457.

Breheny, Richard, Napoleon Katsos and John Williams. 2006. Are generalised scalar implicatures generated by default? An on-line investigation into the role of context in generating pragmatic inferences. Cognition 100: 434-463.

Clark, Herbert and Peter Lucy. 1975. Inferring what was meant from what was said. Journal of Verbal Learning and Verbal Behavior 14: 56-72.

Forster, Kenneth I. and Jonathan C. Forster. 2003. DMDX: A Windows display program with millisecond accuracy. Behavior Research Methods, Instruments, \& Computers 35: 116-124.

Garrett, Merrill F. and Robert M. Harnish. 2007. Experimental pragmatics: Testing for Implicitures. Pragmatics \& Cognition 15: 65-90.

Garrett, Merrill F. and Robert M. Harnish. 2009. Q-Phenomena, I-Phenomena and Impliciture: Some experimental pragmatics. International Review of Pragmatics 1: 84-117. 
Implied content and context

Gibbs, Raymond W. 1979. Contextual Effects in Understanding Indirect Requests. Discourse Processes 2: 1-10.

Gibbs, Raymond W. and Jessica F. Moise. 1997. Pragmatics in understanding what is said. Cognition 62: 51-74.

Giora, Rachel. 1999. On the priority of salient meanings: Studies of literal and figurative language. Journal of Pragmatics 31: 919-929.

Glucksberg, Sam, Patricia Gildea and Howard B. Bookin. 1982. On Understanding Nonliteral Speech: Can People Ignore Metaphors? Journal of Verbal Learning and Verbal Behavior 21: 85-98.

Grice, Paul H. 1975. Logic and Conversation. In P. Cole and J. Morgan (eds.), Syntax and Semantics, Volume 3: Speech Acts, New York: Academic Press. Reprinted in S. Davis (ed.). 1991. Pragmatics: A Reader, 305-315. Oxford: Oxford University Press.

Levinson, Stephen. 1995. Three Levels of Meaning. In F. Palmer (ed.), Grammar and Meaning, 90-115. Cambridge: Cambridge University Press.

Levinson, Stephen. 2000. Presumptive Meanings. Cambridge, MA: MIT Press.

Ortony, Andrew, Diane L. Schallert, Ralph E. Reynolds and Stephen J. Antos. 1978. Interpreting Metaphors and Idioms: Some Effects of Context on Comprehension. Journal of Verbal Learning and Verbal Behavior 1:465-477.

Recanati, Francois. 1993. Direct Reference. Cambridge, MA: Blackwell.

Recanati, Francois. 1995. The alleged priority of literal interpretation. Cognitive Science 19: 207-232.

Sperber, Dan and Deirdre Wilson. 1986. Relevance. Cambridge, MA: Harvard 
Implied content and context

University Press. 
Implied content and context

\section{Biographical notes:}

Robert M. Harnish, Ph.D. in Philosophy and Linguistics (MIT) was Professor of Philosophy and of Linguistics at the University of Arizona (1971-2005), and thereafter Professor Emeritus at Arizona until his death in 2011. His main research interests were in pragmatics, early analytic philosophy (especially Frege), and cognitive science. He co-authored (with K. Bach) Linguistic Communication and Speech Acts (1979), and authored Minds, Brains, Computers (2002).

Merrill F. Garrett, Ph.D. (University of Illinois). He was on the faculty of Massachusetts Institute of Technology (1968-87), a Professor of Psychology and Linguistics at University of Arizona (1987-2008), and is currently Professor Emeritus at Arizona. His research area is psycholinguistics, with theoretical and experimental publications in areas of language production, comprehension, and development.

Dusana Dorjee, Ph.D. in Psychology (University of Arizona) is a lecturer in the School of Psychology at Bangor University in the UK. She is interested in experimental research in semantics and pragmatics which integrates philosophical, psycholinguistic and neuroscientific perspectives. 
Implied content and context

Table 1:

Context compliance rates for implicitures embedded in enabling and canceling contexts in Experiment 2.

\begin{tabular}{lcc}
\hline $\begin{array}{l}\text { Impliciture } \\
\text { Type }\end{array}$ & \multicolumn{2}{c}{ Context Type } \\
Enabling & Canceling \\
\hline Locative & 97 & 88 \\
Temporal & 99 & 87 \\
Possession & 96 & 90 \\
\hline Overall & 97 & 88 \\
\hline
\end{tabular}


Implied content and context

Table 2

Experiment 2: Averages and differences (results in the enabling condition subtracted from results in the canceling condition) for context reading times per line, reading times of implicitures embedded as final sentences in contexts and decision reaction times for the impliciture/non-impliciture probes.

\begin{tabular}{|c|c|c|c|c|c|c|}
\hline \multirow{2}{*}{$\begin{array}{l}\text { Context type } \\
\text { Locative }\end{array}$} & \multicolumn{2}{|c|}{$\begin{array}{l}\text { Context reading } \\
\text { Difference }\end{array}$} & \multicolumn{2}{|c|}{$\begin{array}{r}\text { Impliciture reading } \\
\text { Difference } \\
\end{array}$} & \multicolumn{2}{|c|}{$\begin{array}{r}\text { Decision RT } \\
\text { Difference }\end{array}$} \\
\hline & & & & & & \\
\hline Enabling & 1074 & 19 & 959 & -6 & 1077 & $71^{*}$ \\
\hline Canceling & 1093 & & 953 & & 1148 & \\
\hline \multicolumn{7}{|l|}{ Temporal } \\
\hline Enabling & 1223 & 21 & 1044 & $119^{* *}$ & 1290 & $229^{* *}$ \\
\hline Canceling & 1244 & & 1163 & & 1519 & \\
\hline \multicolumn{7}{|l|}{ Possession } \\
\hline Enabling & 1166 & 13 & 1068 & $65^{*}$ & 1204 & $115^{*}$ \\
\hline Canceling & 1179 & & 1133 & & 1319 & \\
\hline \multicolumn{7}{|l|}{ Overall } \\
\hline Enabling & 1154 & 25 & 1024 & $59^{*}$ & 1190 & $129^{*}$ \\
\hline Canceling & 1179 & & 1083 & & 1319 & \\
\hline
\end{tabular}


Implied content and context

Fig. 1. Example of the stimulus presentation sequence in Experiment 1.

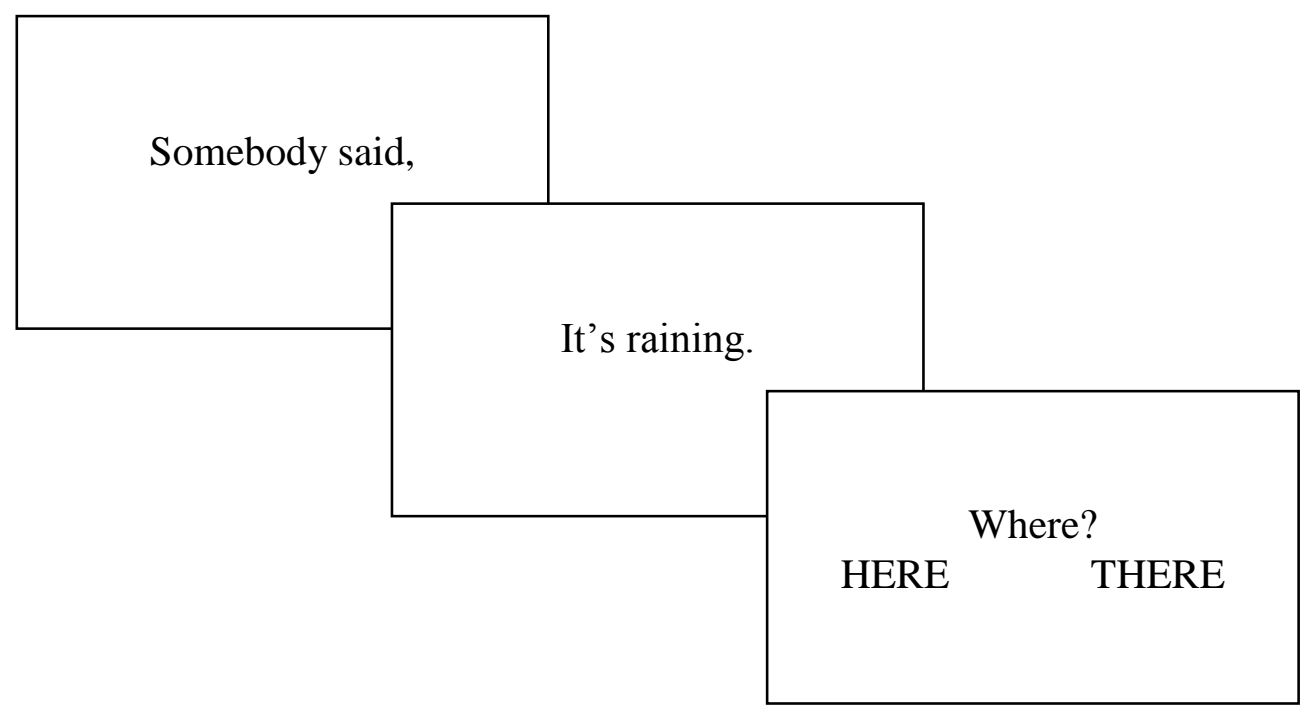


Fig 2. Examples of enabling and canceling contexts in Experiment 2.

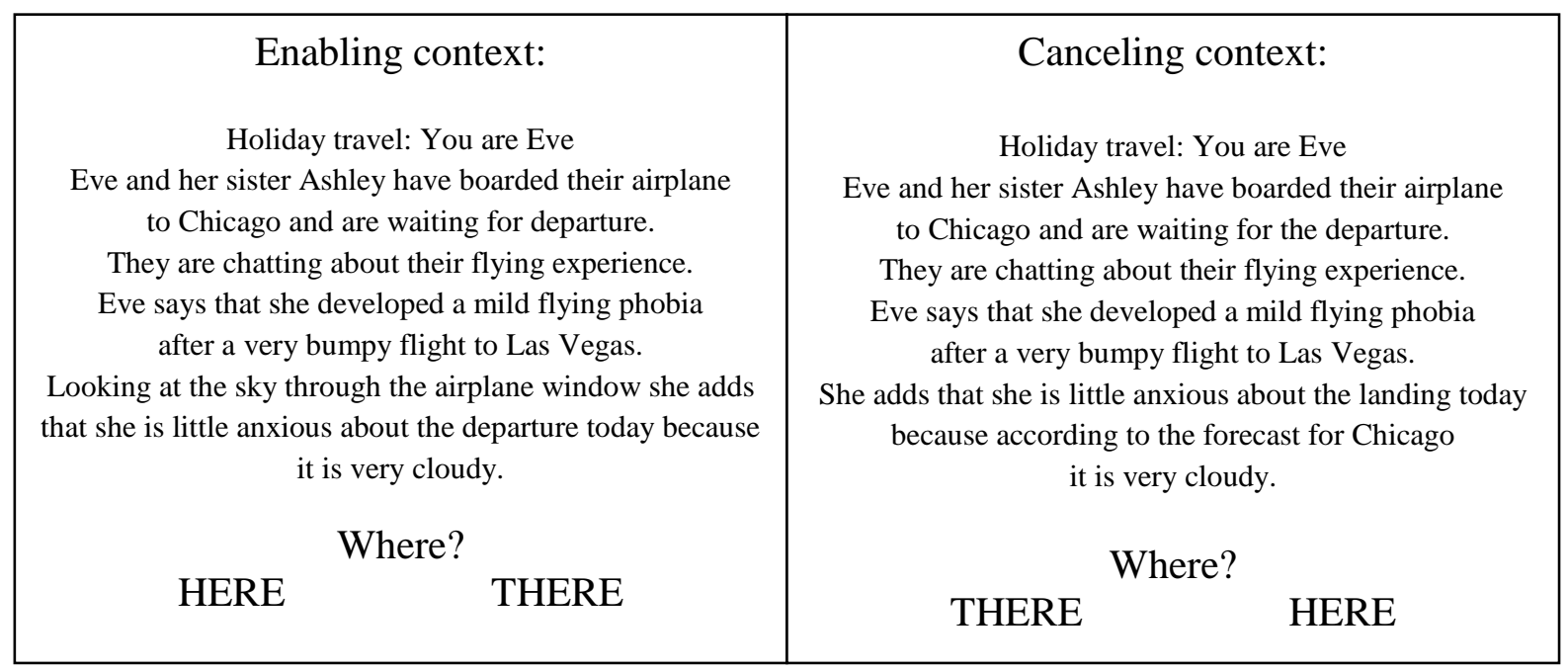


Implied content and context

Appendix A: Examples of implicitures used Experiments 1 and 2.

Locative implicitures:

It's raining.

It's a beautiful afternoon

It's dusty and smelly.

It's very quiet.

It's a calm and peaceful night.

Temporal implicitures:

I've had breakfast.

I've overslept.

I have had dessert.

I've already had supper.

I've baked a cake.

Posession implicitures:

She cautiously flexed a leg.

She lifted a finger.

He chipped a front tooth.

He carefully inspected both hands.

He tugged on an ear lobe. 
Implied content and context 